\title{
A Method for Estimating Gas Pressure in 3013 Containers Using an ISP Database Query
}

\author{
G. P. Friday \\ L. G. Peppers \\ D. K. Veirs
}

July 2008

Savannah River National Laboratory

Washington Savannah River Company

Savannah River Site

Aiken. SC 29808 


\section{DISCLAIMER}

This report was prepared for the United States Department of Energy under Contract No. DE-AC09-96SR18500 and is an account of work performed under that contract. Neither the United States Department of Energy, nor WSRC, nor any of their employees makes any warranty, expressed or implied, or assumes any legal liability or responsibility for accuracy, completeness, or usefulness, of any information, apparatus, or product or process disclosed herein or represents that its use will not infringe privately owned rights. Reference herein to any specific commercial product, process, or service by trade name, trademark, name, manufacturer or otherwise does not necessarily constitute or imply endorsement, recommendation, or favoring of same by Washington Savannah River Company or by the United States Government or any agency thereof. The views and opinions of the authors expressed herein do not necessarily state or reflect those of the United States Government or any agency thereof.

Printed in the United States of America

Prepared For

U.S. Department of Energy 


\section{REVIEWS AND APPROVALS}

\begin{tabular}{lc}
\hline G. P. Friday, Author, SRNL & Date
\end{tabular}

L.G. Peppers, Author, LANL Date

D.K. Veirs, Author, LANL

Date

J.W. McClard, SRS MIS Representative, Technical Reviewer

Date

L.A. Worl, Project Lead, LANL

Date 


\section{TABLE OF CONTENTS}

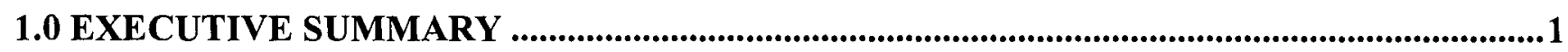

2.0 INTRODUCTION................................................................................................................................

3.0 BACKGROUND ……................................................................................................................................

4.0 CALCULATING GAS PRESSURE - THE MATH.................................................................4

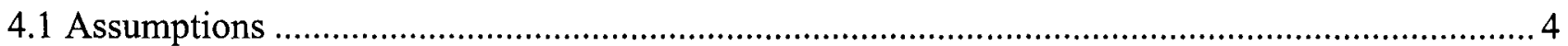

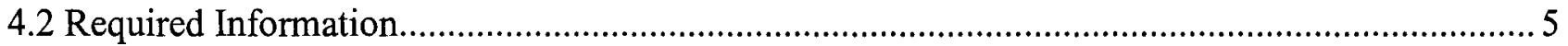

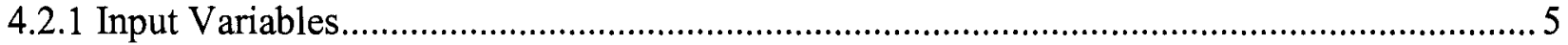

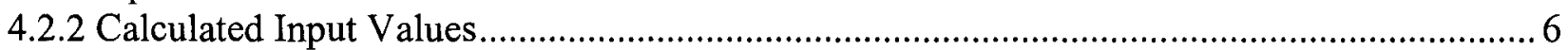

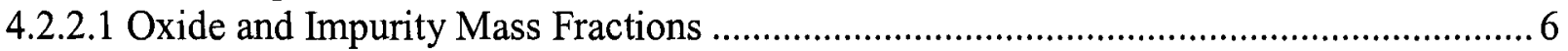

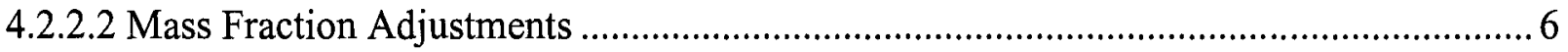

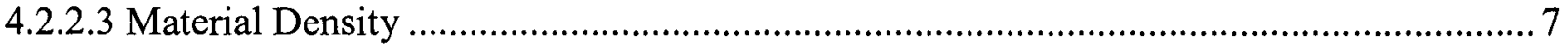

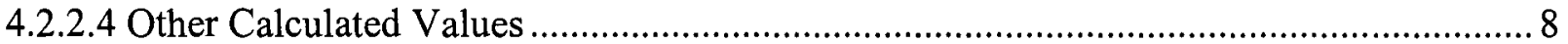

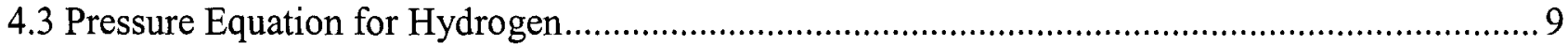

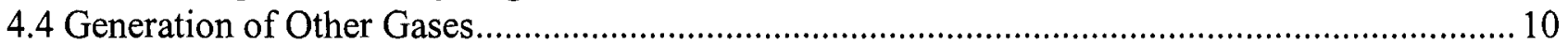

4.5 Total Container Pressure and Adjustments for Temperature ……........................................... 10

\subsection{APPLICATION OF THE MODEL TO THE ISP DATA BASE - THE QUERY ......................13}

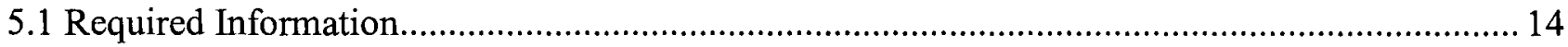

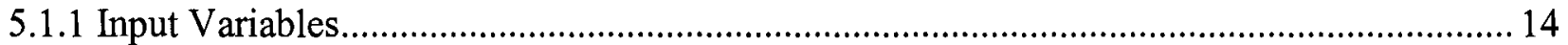

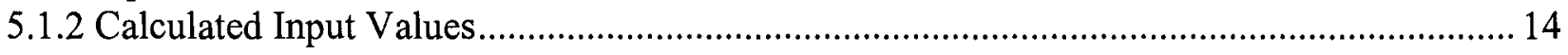

6.0 VERIFICATION OF CALCULATIONS - AN EXAMPLE ...............................................................17

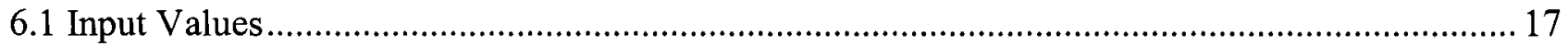

6.2 Density, Volume, and Temperature Calculations.................................................................. 17

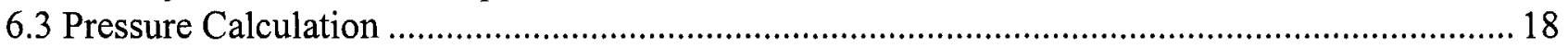

7.0 RESULTS AND DISCUSSION ...............................................................................................................19

8.0 CONCLUSIONS ..............................................................................................................................21

9.0 REFERENCES..............................................................................................................................21 


\subsection{EXECUTIVE SUMMARY}

The U.S. Department of Energy's Integrated Surveillance Program (ISP) is responsible for the storage and surveillance of plutonium-bearing material. During storage, plutonium-bearing material has the potential to generate hydrogen gas from the radiolysis of adsorbed water. The generation of hydrogen gas is a safety concern, especially when a container is breached within a glove box during destructive evaluation. To address this issue, the DOE established a standard (DOE, 2004) that sets the criteria for the stabilization and packaging of material for up to 50 years. The DOE has now packaged most of its excess plutonium for long-term storage in compliance with this standard. As part of this process, it is desirable to know within reasonable certainty the total maximum pressure of hydrogen and other gases within the 3013 container if safety issues and compliance with the DOE standards are to be attained. The principal goal of this investigation is to document the method and query used to estimate total (i.e. hydrogen and other gases) gas pressure within a 3013 container based on the material properties and estimated moisture content contained in the ISP database.

Initial attempts to estimate hydrogen gas pressure in 3013 containers was based on G-values (hydrogen gas generation per energy input) derived from small scale samples. These maximum G-values were used to calculate worst case pressures based on container material weight, assay, wattage, moisture content, container age, and container volume. This paper documents a revised hydrogen pressure calculation that incorporates new surveillance results and includes a component for gases other than hydrogen. The calculation is produced by executing a query of the ISP database. An example of manual mathematical computations from the pressure equation is compared and evaluated with results from the query. Based on the destructive evaluation of 17 containers, the estimated mean absolute pressure was significantly higher $(\mathrm{P}<.01)$ than the mean GEST pressure. There was no significant difference $(\mathrm{P}>10)$ between the mean pressures from $\mathrm{DR}$ and the calculation. The mean predicted absolute pressure was consistently higher than GEST by an average difference of $57 \mathrm{kPa}(8 \mathrm{psi})$. The mean difference between the estimated pressure and digital radiography was $11 \mathrm{kPa}(2 \mathrm{psi})$. Based on the initial results of destructive evaluation, the pressure query was found to provide a reasonably conservative estimate of the total pressure in 3013 containers whose material contained minimal moisture content. 


\subsection{INTRODUCTION}

The storage and surveillance of plutonium-bearing materials by the U.S. Department of Energy (DOE) are important components of national nuclear defense strategy. The DOE Standard, DOE-STD-3013, sets the criteria for stabilization and packaging of plutonium-bearing so that the material can be safely stored for up to 50 years. The Standard also requires a surveillance program for these containers. The Integrated Surveillance Program (ISP) is the DOE complex-wide surveillance program that fulfills this requirement. The ISP consists of two secondary programs: (1) the shelf-life program, which monitors the behavior of selected materials under laboratory conditions (i.e., small scale studies), and (2) the field surveillance program which evaluates 3013 containers and materials during storage (i.e., nondestructive and destructive evaluation).

While in storage, plutonium bearing material may generate hydrogen gas from the hydrolysis of adsorbed water. The standard requires the 3013 container to have a minimum design pressure of 4,927 $\mathrm{kPa}$ (699 psig). This specified design pressure is considered sufficient to contain the pressure generated by the mass of the plutonium oxide under "worst case" conditions of $0.5 \mathrm{wt} \%$ moisture, 19 watts (w) heat generation, $211{ }^{\circ} \mathrm{C}\left(412{ }^{\circ} \mathrm{F}\right)$ gas temperature, and all of the water in the material is radiolyzed to hydrogen (DOE, 2004).

An estimated pressure that takes into account the known material properties, moisture content, and hydrogen gas generation behavior of real materials is desired in support of the destructive evaluation process. This was initially achieved using results from the small scale investigations. The approach has been revised as the knowledge of the material became better understood. In this revision, the consumption of water and a destruction term has been incorporated into the hydrogen gas generation calculation. This approach has been described and applied to Master Blend material in Large-Scale containers with three different water contents and for one small-scale material (Berg, 2007a). The approach was required to reproduce the hydrogen gas generation behavior in MIS material 011589A (Berg, 2007b). This was initially achieved as part of the small scale investigations and has been revised as the knowledge of the material became better understood.

The objectives of this paper are to (1) briefly summarize the historical development of estimating gas pressure within the ISP database, (2) document a revised hydrogen pressure calculation that incorporates surveillance results up to 2007, (3) document how the calculation is applied to the ISP data base using mathematical computations and examples, and (4) compare the predicted total absolute pressure with results from digital radiography and destructive evaluation. This pressure calculation is based on conservative values and its appropriateness is limited to upper bounding conditions or maximum estimated total pressure within the 3013 container. Actual pressures within a 3013 container are expected to be lower because (1) the moisture content measurement is conservative, (2) the hydrogen gas generation behavior bounds the behavior from the worst case material, and (3) the other gases that are included in the calculation are partially an artifact of aging the calcined MIS samples in glove box air prior to surveillance. Future revisions may be necessary as analysis of hydrogen gas generation behavior of real materials is completed. 


\subsection{BACKGROUND}

The Surveillance Program Authority (SPA) requested a reasonably conservative prediction of the pressure inside the 3013 containers prior to its surveillance. The initial attempt (Peppers et al. 2005) to estimate the pressure in 3013 containers was based on G-values (hydrogen gas generation per energy input) derived from small scale samples and applied to individual 3013 containers. Initial G-values for hydrogen gas generation were calculated from small-scale test data for times ranging from 6 months to a little over one year for individual Materials Identification and Surveillance (MIS) samples. The MIS samples were binned into four groups by material similarity and each group assigned a maximum Gvalue that bounded the hydrogen gas generation within the group. These maximum G-values were used to calculate worst case pressures for each 3013 container based on container material weight, assay, wattage, moisture content, container age and container volume.

The worst case pressure calculation using an initial G-value results in the hydrogen gas pressure increasing linearly with time which is sufficiently bounding to be conservative even for facility level safety basis evaluations. The calculation does not take into account consumption of the water or subsequent reactions of the hydrogen gas, which are necessary for defining a more realistic pressure estimate for surveillance purposes that is consistent with small scale studies. Small scale studies indicate that the hydrogen gas generation rate decreases with time. Therefore, the hydrogen G-value decreases with time. The use of initial G-values in pressure calculations therefore significantly overestimates the hydrogen gas pressure at longer times.

The small scale studies also showed that hydrogen was not generated in any significant amount when salt was not present. Generation of other gasses such as $\mathrm{N}_{2}, \mathrm{~N}_{2} \mathrm{O}, \mathrm{CH}_{4}, \mathrm{CO}$, and $\mathrm{CO}_{2}$ was observed at relatively low pressures. The ability to accurately estimate pressure of these gases is unreliable. However, due to their low partial pressure, this is not a significant issue. 


\subsection{CALCULATING GAS PRESSURE - THE MATH}

The following calculation is specific to the generation of hydrogen gas from plutonium oxide. A component to account for other gases is included to provide an estimate of total absolute pressure. This calculation uses information on DOE-STD-3013 containers from the ISP database, and is limited to the oxide items in the database.

\subsection{Assumptions}

The calculation of pressure assumes that the gases within a 3013 container behave as an ideal gas. The relationship between the four principal variables (i.e., amount of gas, absolute pressure, volume, and absolute temperature) is expressed as the ideal gas law:

$\mathrm{PV}=\mathrm{nRT}$

where

$$
\begin{aligned}
& \mathrm{P}=\text { pressure }(\mathrm{kPa}) \\
& \mathrm{V}=\text { volume }(\mathrm{L}) \\
& \mathrm{n}=\text { moles of } \text { gas }=\text { mass } / \text { molecular weight } \\
& \mathrm{R}=\text { gas constant }=8.3145 \mathrm{~L}-\mathrm{kPa} \mathrm{K}^{-1}-\mathrm{mol}^{-1} \\
& \mathrm{~T}=\text { temperature }(\mathrm{K})
\end{aligned}
$$

Other assumptions of this calculation method include the following:

- Pressure buildup in containers by hydrogen generation from radiolysis of water can be estimated using the material properties and the moisture content.

- Oxygen released by radiolysis is absorbed by the material. This is generally but not strictly true in the small scale studies. Oxygen gas is not considered as part of this pressure calculation.

- Generation of other gases such as $\mathrm{N}_{2}, \mathrm{~N}_{2} \mathrm{O}, \mathrm{CH}_{4}, \mathrm{CO}$, and $\mathrm{CO}_{2}$ are considered negligible relative to the rate of hydrogen generation. Based on earlier small scale results, best engineering judgment, and destructive evaluation results, the cumulative pressure from these gases is not expected to exceed $50 \mathrm{kPa}$ absolute pressure at $55^{\circ} \mathrm{C}$.

- Hydrogen generation behavior of the Materials Identification and Surveillance (MIS) items is representative of the population of materials stored in 3013 containers.

- G values used in this analysis are constant and were assigned based on the presence or absence of chlorine in the material.

- Uranium present in the material is in the $\mathrm{U}_{3} \mathrm{O}_{8}$ oxidation state. 


\subsection{Required Information:}

\subsubsection{Input Variables}

Input variables for performing the hydrogen pressure calculation include:

- Volume (L) of inner 3013 container: $V_{\text {container }}$

- Mass (kg) of convenience can and lid: $m_{C C}=\frac{m_{C C(g)}}{1000 \mathrm{~g} / \mathrm{kg}}$

- Density $\left(\mathrm{g} / \mathrm{cm}^{3}\right)$ of stainless steel: $\rho_{S S}=8.0$

- Net mass (kg) of the material: $m=\frac{m_{(\mathrm{g})}}{1000 \mathrm{~g} / \mathrm{kg}}$

- Net mass (kg) of Pu: $m_{P u}=\frac{m_{P u(g)}}{1000 g / k g}$

- Net mass $(\mathrm{kg})$ of $\mathrm{U}: m_{U}=\frac{m_{U(g)}}{1000 \mathrm{~g} / \mathrm{kg}}$

- Net mass (kg) of Am: $m_{A m}=\frac{m_{A m(g)}}{1000 \mathrm{~g} / \mathrm{kg}}$

- Net mass (kg) of Np: $m_{N p}=\frac{m_{N p(g)}}{1000 g / k g}$

- Mass fraction of plutonium: $f_{P u}=\frac{m_{P u}}{m}$

- Mass fraction of uranium: $f_{U}=\frac{m_{U}}{m}$

- Mass fraction of americium: $f_{A m}=\frac{m_{A m}}{m}$

- Mass fraction of neptunium: $f_{N p}=\frac{m_{N p}}{m}$

- Mass fraction of water: $f_{\mathrm{H}_{2} \mathrm{O}}=w t . \% \mathrm{H}_{2} \mathrm{O} / 100$

- Total radioactive decay energy (w): $Q$

- Gas constant: $\mathrm{R}=8.3145 \frac{\mathrm{kPa}-\mathrm{L}}{\mathrm{mol}-\mathrm{K}}$

- Density $\left(\mathrm{g} / \mathrm{cm}^{3}\right)$ of plutonium oxide: $\quad \rho_{P_{u O_{2}}}=11.5 \frac{\mathrm{g}}{\mathrm{cm}^{3}}$

- Density of uranium oxide: $\rho_{U_{3} O_{8}}=8.38 \frac{\mathrm{g}}{\mathrm{cm}^{3}}$

- Density of neptunium oxide: $\rho_{N p O_{2}}=11.1 \frac{\mathrm{g}}{\mathrm{cm}^{3}}$

- Density of americium oxide: $\rho_{A m O_{2}}=11.7 \frac{\mathrm{g}}{\mathrm{cm}^{3}}$ 
- Density of water: $\rho_{\mathrm{H}_{2} \mathrm{O}}=1.0 \frac{\mathrm{g}}{\mathrm{cm}^{3}}$

- Density of all other material: $\rho_{\text {salts }}=2.5 \frac{\mathrm{g}}{\mathrm{cm}^{3}}$

Note: because much of the other material is salts, the subscript"salts" is used for all non-actinide impurity material.

- Time and date container was sealed: $t_{\text {initial }}$

- Current time and date: $t_{\text {current }}$

\subsubsection{Calculated Input Values:}

\subsubsection{Oxide and Impurity Mass Fractions:}

Mass fraction of plutonium oxide: $\mathrm{f}_{\mathrm{PuO}_{2}}=\mathrm{f}_{\mathrm{Pu}} \times 1.134$

Mass fraction of uranium oxide: $f_{U_{3} O_{8}}=f_{U} \times 1.179$

Mass fraction of americium oxide: $f_{\mathrm{NpO}_{2}}=f_{\mathrm{Np}} \times 1.132$

Mass fraction of neptunium oxide: $f_{\mathrm{AmO}_{2}}=f_{\mathrm{Am}} \times 1.135$

Mass fraction of all actinides + water: $f_{T-S}=f_{\mathrm{PuO}_{2}}+f_{\mathrm{U}_{3} \mathrm{OB}}+f_{\mathrm{NpO}_{2}}+f_{\mathrm{AmO}_{2}}+f_{\mathrm{H}_{2} \mathrm{O}}$

Mass fraction of the salts: $f_{\text {salts }}$ (defined below)

\subsubsection{Mass Fraction Adjustments:}

The mass fraction of all of the actinides plus water can exceed $1.00(100 \%)$ due to errors in the assay. The inherent error in the assay for uranium is much greater than the errors in the assays of the other actinides. Thus, if $f_{T-S}$ exceeds 1.00 by a small amount (e.g., 0.02 ), the error is probably attributable to random error from the assays. If $f_{T-S}$ exceeds 1.00 by more than 0.02 and uranium is present, the error most likely comes from the uranium assay. These observations are expressed in the following corrections for when $f_{T-S}$ exceeds 1.00 . In order to make the mathematics more tractable, the water fraction must be adjusted for the density calculation $\left(f_{\mathrm{H}_{2} \mathrm{Od}}=f_{\mathrm{H}_{2} \mathrm{O}}\right)$. The water fraction will remain as measured for the pressure calculation. Water fractions less than zero in the ISP database will be set to zero for all calculations. 
If $f_{T-S}<1$ is true then:

$$
f_{\text {salts }}=1-f_{T-S}
$$

Else If $\left(f_{T-S}-1\right)<0.02$ is true then all components are adjusted proportionally:

$$
f_{P_{u} O_{2}}=\frac{f_{P u O_{2}}}{f_{T-S}} ; \quad f_{U_{3} O_{8}}=\frac{f_{U_{3} O_{8}}}{f_{T-S}} ; \quad f_{N p O_{2}}=\frac{f_{N p O_{2}}}{f_{T-S}} ; \quad f_{A m O_{2}}=\frac{f_{A m O_{2}}}{f_{T-S}} ; \quad f_{H_{2} O d}=\frac{f_{H_{2} O}}{f_{T-S}}
$$

Else If $f_{U_{3} O_{8}}<\left[f_{T-S}-1\right]$ is true then all components are adjusted proportionally:

$$
f_{P_{u} O_{2}}=\frac{f_{P_{u} O_{2}}}{f_{T-S}} ; \quad f_{U_{3} O_{8}}=\frac{f_{U_{3} O_{8}}}{f_{T-S}} ; \quad f_{N p O_{2}}=\frac{f_{N p O_{2}}}{f_{T-S}} ; \quad f_{A m O_{2}}=\frac{f_{A m O_{2}}}{f_{T-S}} ; \quad f_{H_{2} O d}=\frac{f_{H_{2} O}}{f_{T-S}}
$$

Note: in this case, the amount of uranium present cannot account for the assay errors, therefore all components are adjusted proportionally.

Else $f_{U_{3} O_{8}}>\left[f_{T-S}-1\right]$ is true then:

$$
f_{U_{3} O_{8}}=f_{U_{3} O_{8}}-\left[f_{T-S}-1\right]
$$

\subsubsection{Material Density:}

$$
\text { Overall density of the material: } \rho=\frac{1}{\frac{f_{\mathrm{PuO}_{2}}}{\rho_{\mathrm{Pu}_{2}}}+\frac{f_{\mathrm{U}_{3} \mathrm{O}_{8}}}{\rho_{U_{3} \mathrm{O}}}+\frac{f_{\mathrm{NpO}_{2}}}{\rho_{\mathrm{NpO}_{2}}}+\frac{f_{\mathrm{AmO}_{2}}}{\rho_{\mathrm{AmO}_{2}}}+\frac{f_{\mathrm{H}_{2} \mathrm{Od}}}{\rho_{\mathrm{H}_{2} \mathrm{O}}}+\frac{f_{\text {salt }}}{\rho_{\text {salt }}}}
$$

A comparison of the calculated versus the measured density for the MIS Items (only those items that had density measurements made and had all of the required information to perform the calculation were used) is shown in Figure 1. These data show a reasonably good correlation between the calculated and measured results. Inaccuracies in the assay of the material, use of an average density for salt components (known salt components vary from about 1.9 to 3.5 depending on the composition), and the inability of calorimetry/gamma spectroscopy to detect ${ }^{238} \mathrm{U}$, account for most of the deviation between the calculated and measured results. Most of the large deviations shown in Figure 1 result in lower calculated vs. actual densities which will result in conservative estimates of container pressure. 


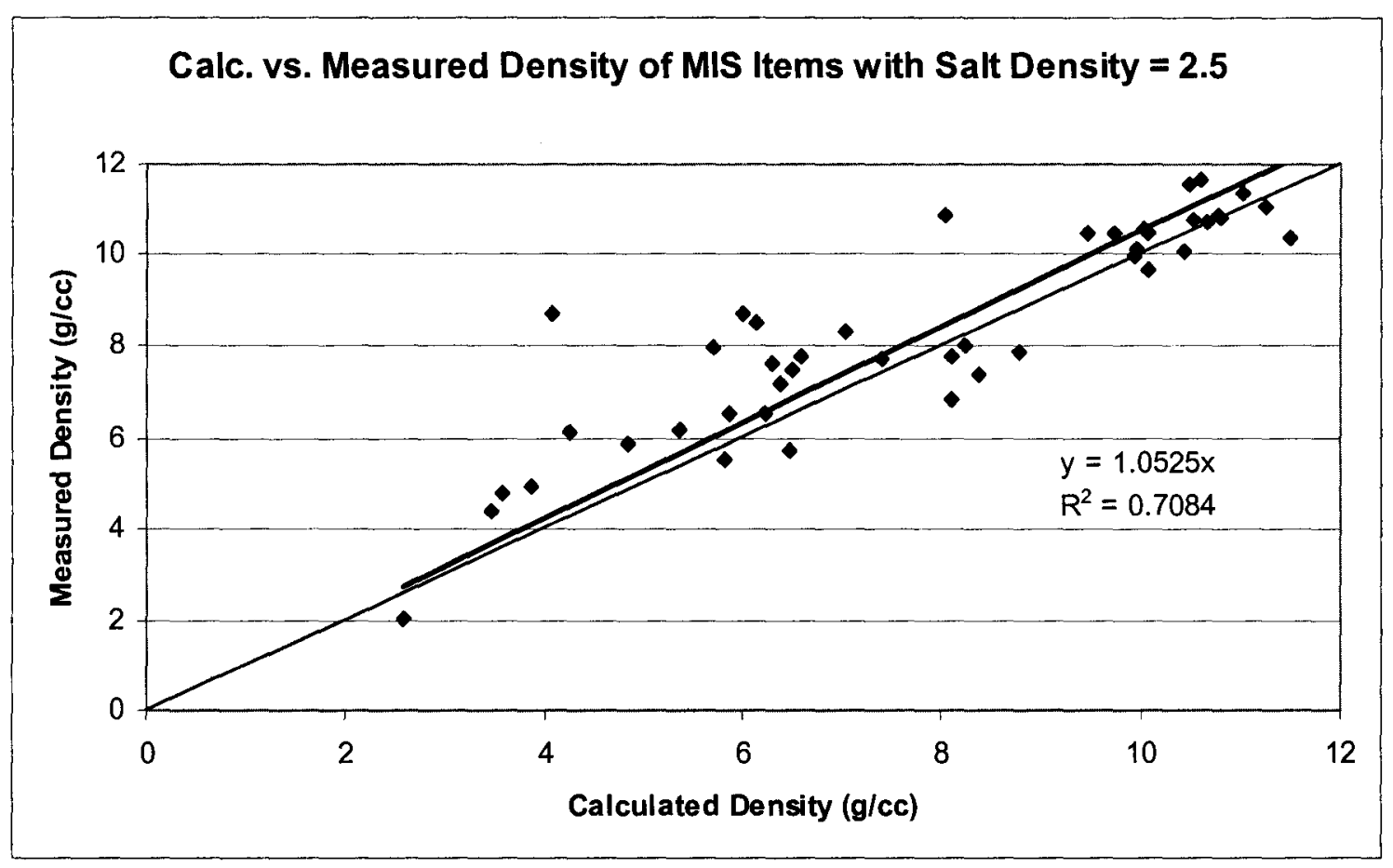

Figure 1. Calculated densities of MIS items using calorimetry/gamma spectroscopy measurements vs. measured density from gas pycnometry. Non-actinide components other than water were assumed to have an average density of 2.5 (Peppers et al. 2005).

\subsubsection{Other Calculated Values:}

Gas Volume

The volume of the container that is available to the gas is based on the inner container volume. In each inner oxide container there is a convenience can that holds the material. The volume occupied by the convenience container and material must be subtracted from the inner container's inner volume as:

$$
\text { Gas volume (L): } V_{\text {Gas }}=V_{\text {Container }}-V_{\text {Material }}-V_{\text {Convenience Can }}=V_{\text {Container }}-\frac{m}{\rho}-\frac{m_{C C}}{\rho_{S S}}
$$

The inner can volume is site specific. The volumes used in these calculations are the minimum volumes shown in Table 1. 
Table 1. Inner container volume (L) of 3013's by packaging location.

\begin{tabular}{|c|c|c|c|}
\hline Site & $\begin{array}{l}\text { Minimum } \\
\text { Volume (L) }\end{array}$ & $\begin{array}{l}\text { Maximum } \\
\text { Volume (L) }\end{array}$ & Reference \\
\hline Hanford & 2.089 & 2.110 & Hackney (2007b) \\
\hline LANL & $2.286 \ddagger$ & -- & See table footnote. \\
\hline LLNL & 2.174 & 2.217 & $t$ \\
\hline RFETS & 2.174 & 2.217 & Hackney (2007a) \\
\hline SRS & 2.089 & 2.110 & Hackney (2007b \\
\hline
\end{tabular}

$\dagger$ LLNL uses the same inner container as RFETS and is therefore assumed to have the same volume.

$\ddagger$ Nominal inside volume, minimum and maximum not stated

\section{Average Gas Temperature}

The average gas temperature inside inner container is calculated using the following equation:

$$
T_{C}\left({ }^{\circ} K\right)=3 Q+1.6 Q+25+273=4.6 Q+298
$$

where

$25^{\circ} \mathrm{C}$ is the ambient temperature,

273 converts degrees Celsius to Kelvin,

$1.6\left({ }^{\circ} \mathrm{K} / \mathrm{w}\right) \times Q(\mathrm{w})$ is the increase going from the outer container wall to the inner container wall, and $3(\mathrm{~K} / \mathrm{w}) \times Q(\mathrm{w})$ is the average increase due to the material using the thermal model derived by Bielenberg et al (2006).

\section{Container Age}

The container age is based on the date that the inner container was welded and is calculated to the date of interest as:

Time (days): $\quad \Delta t=t_{\text {current }}-t_{\text {initial }}$

or

Time (seconds): $t=\Delta t_{\text {(days) }} \times 86400_{(\text {sec onds/day })}$

\subsection{Pressure Equation for Hydrogen}

The following equation calculates hydrogen pressure from plutonium oxide as a function of time. The $\mathrm{G}$ value, which is defined as the amount of hydrogen generated per joule of radiation energy deposited into the water molecules within the plutonium-bearing material, varies by material type. The $\mathrm{G}$ value (nmol/w-s) for oxides containing chloride is 200; for material lacking chloride it is 5, and the value is zero for metals. Density and volume are defined in Equations 11 and 12, respectively. Average gas temperature is calculated using Equation 13. Container age is calculated using equation 14. 


$$
P_{\mathrm{H}_{2}}(t)=\frac{C}{k \cdot \frac{R T}{V_{\text {Gas }}}-C} \cdot \frac{R T}{V_{\text {Gas }}} \cdot n_{\mathrm{H}_{2} \mathrm{O}}\left(e^{(-\mathrm{C} \cdot \mathrm{t})}-\mathrm{e}^{\left(-\mathrm{k} \frac{\mathrm{RT}}{\mathrm{V}_{\text {Gas }}} \cdot \mathrm{t}\right)}\right)
$$

where

$$
\mathrm{C}\left(\mathrm{s}^{-1}\right)=\mathrm{G} \times \mathrm{SA} \times \mathrm{f}_{\mathrm{eH}_{2} \mathrm{O}} \times \mathrm{MW}_{\mathrm{H}_{2} \mathrm{O}}
$$

$G=\mathrm{G}$ Value (nmol/w-s) (200 for chloride containing material, 5 for non-chloride containing material)

$S A=$ specific activity $(\mathrm{w} / \mathrm{kg})=Q / m$

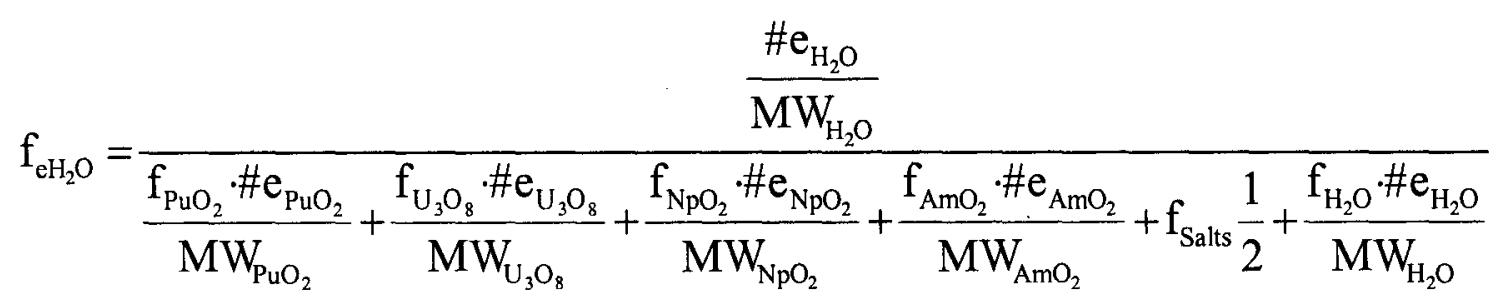

$\# e=$ number of electrons associated with component

$\mathrm{MW}=$ molecular weight (mass) of component

$$
k=7.5 \times 10^{-11} \mathrm{~mol} / \mathrm{s}-\mathrm{kPa}
$$

$$
n_{\mathrm{H}_{2} \mathrm{O}}=\frac{m \cdot f_{\mathrm{H}_{2} \mathrm{O}}}{M W_{\mathrm{H}_{2} \mathrm{O}}}
$$

\subsection{Generation of Other Gases}

As stated previously, generation of other gases such as $\mathrm{N}_{2}, \mathrm{~N}_{2} \mathrm{O}, \mathrm{CH}_{4}, \mathrm{CO}$, and $\mathrm{CO}_{2}$ are considered in the pressure calculation estimate. Based on earlier small scale results and best engineering judgment, these gases are not expected to exceed $50 \mathrm{kPa}$ absolute pressure at $55^{\circ} \mathrm{C}\left(328^{\circ} \mathrm{K}\right)$. Therefore, the total calculated pressure generated in the 3013 container at the time of evaluation is defined as:

$$
\mathrm{P}_{\text {Generated }}=\mathrm{P}_{\mathrm{H}_{2}}+\mathrm{P}_{\text {Other Gasses }}=\mathrm{P}_{\mathrm{H}_{2}\left(\mathrm{~T}_{\mathrm{c}}\right)}+50 \mathrm{kPa}_{328^{\circ} \mathrm{K}}
$$




\subsection{Total Container Pressure and Adjustments for Temperature}

The total pressure in the inner container is the combination of the pressure of the gas generated after welding and the pressure of the gas present at welding.

$$
P_{\text {Total }}=P_{\text {Initial }}+P_{\text {Generated }}=P_{\text {Atm }}+P_{H_{2}}+P_{\text {OtherGasses }}
$$

where:

$P_{\text {Total }}$ is the total inner container pressure at the temperature of interest

$P_{\text {Initial }}=P_{A t m}$ is the atmospheric pressure at the welding site at ambient temperature $\left(298^{\circ} \mathrm{K}\right)$

$P_{\text {Generated }}$ is the pressure of hydrogen at temperature $T_{C}$ and other gasses at $328^{\circ} \mathrm{K}$

Because atmospheric pressure varied by packaging location, $P_{\text {Initial }}$ is based on the altitude of the generation sites (Table 2).

Table 2. Altitude and atmospheric pressure by packaging location.

\begin{tabular}{|c|c|c|c|c|}
\hline \multirow[t]{2}{*}{ Generation Site } & \multicolumn{2}{|c|}{ Altitude } & \multicolumn{2}{|c|}{ Atmospheric Pressure } \\
\hline & $\mathbf{F t}$ & $\mathbf{m}$ & psi & $\mathbf{k P a}$ \\
\hline Hanford & 400 & 123 & $\overline{14.4}$ & 99 \\
\hline LANL & 7340 & 2237 & 11.3 & 78 \\
\hline LLNL & 570 & 174 & 14.4 & 99 \\
\hline RFTES & 6,000 & 1,829 & 11.8 & 81 \\
\hline SRS & 150 & 46 & 14.7 & 101 \\
\hline
\end{tabular}

In order to sum the pressures in equation (21), they must be at a common temperature. This requires adjusting the pressures for $\mathrm{H}_{2}$ and other gases to $298 \mathrm{~K}$. Because atmospheric pressure (Table 2) is given at ambient temperature, no adjustment is necessary. Once the three pressure estimates are at a common temperature, their total can be adjusted to other desired temperatures.

Equation 15 estimates hydrogen pressure at an average temperature of $4.6^{\circ} \mathrm{K} / \mathrm{w} \mathrm{Q}+298^{\circ} \mathrm{K}$ (Equation 13). It is assumed that the ambient temperature when the material is placed into the 3013 container is $25^{\circ} \mathrm{C}$. After the container is welded shut, the temperature rises to $4.6^{\circ} \mathrm{K} / \mathrm{w} \mathrm{Q}$ above ambient. Thus, to normalize the hydrogen gas pressure to ambient temperature, the following conversion is applied:

$$
\frac{P_{1}}{P_{2}}=\frac{T_{1}}{T_{2}} \Rightarrow P_{2}=P_{1} \frac{T_{2}}{T_{1}} \Rightarrow P_{298^{\circ} K}=P_{T_{C}} \frac{298}{T_{C}}=P_{T_{C}} \frac{298}{(4.6 Q+298)}
$$

The total absolute pressure (TAP) within the 3013 inner container is derived by summing: (1) the hydrogen pressure adjusted for ambient temperature, (2) the estimated total pressure from other gases at ambient temperature, and (3) the atmospheric pressure for the generation site. Therefore, equation 21 becomes: 


$$
\mathrm{P}_{\text {TAP@ 298K }}=\mathrm{P}_{\text {Amm }}+\left(\mathrm{P}_{\text {Other Gases }} \times \frac{298}{323}\right)+\mathrm{P}_{\mathrm{H}_{2}} \cdot \frac{298}{(4.6 \mathrm{Q}+298)}=\mathrm{P}_{\text {Amm }}+45.4+\mathrm{P}_{\mathrm{H}_{2}} \cdot \frac{298}{(4.6 \mathrm{Q}+298)}
$$

Given that the total absolute pressure is the sum of the gauge pressure and the atmospheric pressure, the total gauge pressure (TGP) at the Savannah River Site can be derived as follows:

$$
\mathrm{P}_{\mathrm{TGP} @ 298 \mathrm{~K}}=\mathrm{P}_{\mathrm{TAP} @ 298 \mathrm{~K}}-\mathrm{P}_{\mathrm{ATM}}
$$

The DOE 3013 Standard specifies a design limit of $4,927 \mathrm{kPa}(699 \mathrm{psig})$ at a temperature of $484^{\circ} \mathrm{K}$ $\left(412^{\circ} \mathrm{F}\right)$ which equates to the worst case temperature during transportation (DOE 2004). Thus, to adjust the gauge pressure to the DOE standard of $484^{\circ} \mathrm{K}\left(412^{\circ} \mathrm{F}\right)$, the following relationship was used:

$$
\mathrm{P}_{\mathrm{TGP} @ 484 \mathrm{~K}}=\mathrm{P}_{\mathrm{TGP}}\left(\text { at } \mathrm{T}_{\mathrm{C}}\right) \frac{484}{(4.6 \mathrm{Q}+298)}
$$




\subsection{APPLICATION TO THE ISP DATA BASE - THE QUERY}

Data generated from the Materials Identification and Surveillance (MIS) program are stored in the relational data base FSMISP. The principle behind a relational database is that information is partitioned into separate stacks of logically related data, each of which is stored in a separate table in the database (Andersen, 2001). The FSMISP consists of numerous tables which serve as the fundamental objects for information storage and retrieval. Microsoft Access is the database management software that is used to manipulate the FSMISP.

The gas pressure equation is applied to the database using a query. The query, which is written in structured query language (SQL), requires that the date of interest (i.e., "as of date") be entered before it will execute. The SQL language that applies the pressure equation to the data base is shown in Figure 2.

SELECT tblPCDProcessed.[3013ContainerID], tblPCDProcessed.FY06ISPBin, tblPCDConvCan.ConvCanNet, tblPCDConvCan.ConvCanTare, tblPCDMoisture.BestMoisture, tblPCDMoisture.MoisturePercent, tblPCDCalGamma.[Pu Measured (g)], tblPCDCalGamma.[Am Measured (g)], tblPCDCalGamma.[U Measured (g)], tblPCDCalGamma.[Np

Measured (g)], tblPCDProcessed.VollnnerCont, tblPCDInnerCan.InnerCanDateTimeofweld,

[tblPCDCalGamma]![Wattage]*3+[tblPCDCalGamma]![Wattage]*1.6+25+273 AS T,

[tblPCDCalGamma]![Wattage]/[tblPCDConvCan]![ConvCanNet]*1000 AS SA,

IIf([tblPCDMoisture]![MoisturePercent]<0,0,[tblPCDMoisture]![MoisturePercent]/100) AS [f-H2O], nz([Pu Measured $(\mathrm{g})]) / \mathrm{nz}([\mathrm{ConvCanNet]})$ AS [f-Pu], nz([Am Measured (g)])/nz([ConvCanNet]) AS [f-Am], nz([U Measured

$(\mathrm{g})]) / \mathrm{nz}([\mathrm{ConvCanNet}])$ AS [f-U], nz([Np Measured (g)])/nz ([ConvCanNet]) AS [f-Np], (nz ([Pu Measured (g)])+nz([U Measured (g)])+nz ([Am Measured (g)])+nz([Np Measured (g)]))/nz([ConvCanNet]) AS [f-Act], (nz ([Pu Measured $(\mathrm{g})]) / \mathrm{nz}([\mathrm{ConvCanNet}]))^{*} 1.134 \mathrm{AS}[\mathrm{f}-\mathrm{PuO} 2],(\mathrm{nz}([\mathrm{Am} \text { Measured }(\mathrm{g})]) / \mathrm{nz}([\mathrm{ConvCanNet}]))^{*} 1.132 \mathrm{AS}$ [f-AmO2], (nz ([U Measured (g)] $) / \mathrm{nz}([\mathrm{ConvCanNet]}]))^{* 1.179} \mathrm{AS}$ [f-U3O8], (nz([Np Measured (g)])/nz([ConvCanNet]))*1.135 AS [f-NpO2], $\left(\mathrm{nz}([\mathrm{Pu}\right.$ Measured $(\mathrm{g})]) / \mathrm{nz}([\text { ConvCanNet] }))^{*} 1.134+(\mathrm{nz}([\mathrm{U} \text { Measured }(\mathrm{g})]) / \mathrm{nz}([\text { ConvCanNet }]))^{*} 1.179+(\mathrm{nz}([\mathrm{Am}$ Measured $(\mathrm{g})]) / \mathrm{nz}([\mathrm{ConvCanNet}]))^{*} 1.132+(\mathrm{nz}([\mathrm{Np} \text { Measured }(\mathrm{g})]) / \mathrm{nz}([\text { ConvCanNet }]))^{*} 1.135$ AS [f-ActOx],

IIf([tblPCDMoisture]![MoisturePercent] $<0,0$, [tblPCDConvCan]![ConvCanNet]*([tblPCDMoisture]![MoisturePercent]/100) /18.0152) AS [n-H2O], DateDiff("s",[tblPCDInnerCan]![InnerCanDateTimeofweld],[Pressure Calculation End Date]) AS [date dif], DateDiff("d",[tblPCDInnerCan]![InnerCanDateTimeofweld],[Pressure Calculation End Date]) AS [date dif-d], [Pressure Calculation End Date] AS [As of], [f-ActOx] $+[\mathrm{f}-\mathrm{H} 2 \mathrm{O}]$ AS [f-T-S], IIf([f-T-S] $1,1-[\mathrm{f}-\mathrm{T}-\mathrm{S}], 0)$ AS [f-Salt], IIf([f-T$\mathrm{S}]<1,1 /(([\mathrm{f}-\mathrm{PuO} 2] / 11.5)+([\mathrm{f}-\mathrm{U} 3 \mathrm{O} 8] / 8.38)+([\mathrm{f}-\mathrm{AmO} 2] / 11.7)+([\mathrm{f}-\mathrm{NpO} 2] / 11.1)+((1-[\mathrm{f}-\mathrm{T}-\mathrm{S}]) / 2.5)+[\mathrm{f}-\mathrm{H} 2 \mathrm{O}]), \mathrm{IIf}([\mathrm{f}-\mathrm{T}-\mathrm{S}]-$

$1<0.02,1 /((([\mathrm{f}-\mathrm{PuO} 2] /[\mathrm{f}-\mathrm{T}-\mathrm{S}]) / 11.5)+(([\mathrm{f}-\mathrm{U} 3 \mathrm{O} 8] /[\mathrm{f}-\mathrm{T}-\mathrm{S}]) / 8.38)+(([\mathrm{f}-\mathrm{AmO} 2] /[\mathrm{f}-\mathrm{T}-\mathrm{S}]) / 11.7)+(([\mathrm{f}-\mathrm{NpO} 2] /[\mathrm{f}-\mathrm{T}-\mathrm{S}]) / 11.1)+([\mathrm{f}-$ $\mathrm{H} 2 \mathrm{O}] /[\mathrm{f}-\mathrm{T}-\mathrm{S}])), \mathrm{Iff}([\mathrm{f}-\mathrm{U} 3 \mathrm{O} 8]<[\mathrm{f}-\mathrm{T}-\mathrm{S}]-1,1 /((([\mathrm{f}-\mathrm{PuO} 2] /[\mathrm{f}-\mathrm{T}-\mathrm{S}]) / 11.5)+(([\mathrm{f}-\mathrm{U} 3 \mathrm{O} 8] /[\mathrm{f}-\mathrm{T}-\mathrm{S}]) / 8.38)+(([\mathrm{f}-\mathrm{AmO} 2] /[\mathrm{f}-\mathrm{T}-$

$\mathrm{S}]) / 11.7)+(([\mathrm{f}-\mathrm{NpO} 2] /[\mathrm{f}-\mathrm{T}-\mathrm{S}]) / 11.1)+([\mathrm{f}-\mathrm{H} 2 \mathrm{O}] /[\mathrm{f}-\mathrm{T}-\mathrm{S}])), 1 /(([\mathrm{f}-\mathrm{PuO} 2] / 11.5)+(([\mathrm{f}-\mathrm{U} 3 \mathrm{O} 8]-([\mathrm{f}-\mathrm{T}-\mathrm{S}]-1)) / 8.38)+([\mathrm{f}-$ AmO2]/11.7)+([f-NpO2]/11.1)+[f-H2O])))) AS Density, [tb1PCDProcessed]![VolInnerCont]-

[tblPCDConvCan]![ConvCanNet]/([Density]*1000)-[tblPCDConvCan]![ConvCanTare]/(8*1000) AS [V-Gas], (10/18)/([fPuO2] $\left.{ }^{*}(110 / 271)+[\mathrm{f}-\mathrm{AmO} 2]^{*}(111 / 275)+[\mathrm{f}-\mathrm{U} 3 \mathrm{O} 8]^{*}(340 / 833)+[\mathrm{f}-\mathrm{NpO} 2]^{*}(109 / 269)+[\mathrm{f}-\mathrm{H} 2 \mathrm{O}]^{*}(10 / 18)+0.5 *[\mathrm{f}-\mathrm{Salt}]\right)$ AS [fe-H2O], [tblPCDProcessed]![GValue] ${ }^{*}[\mathrm{SA}] *[\mathrm{f}-\mathrm{e}-\mathrm{H} 2 \mathrm{O}]^{*} 18.0152 * 0.000000000001$ AS C, $8.3145 *[\mathrm{~T}] /[\mathrm{V}-\mathrm{Gas}]$ AS $[\mathrm{RT} / \mathrm{V}]$, $0.000000000075 \mathrm{AS} \mathrm{k},[\mathrm{RT} / \mathrm{V}]^{*}[\mathrm{k}]$ AS $\left.[\mathrm{kRT} / \mathrm{V}],\left([\mathrm{C}]^{*}[\mathrm{RT} / \mathrm{V}]^{*}[\mathrm{n}-\mathrm{H} 2 \mathrm{O}]\right) /\left((\mathrm{k}]^{*}[\mathrm{RT} / \mathrm{V}]\right)-[\mathrm{C}]\right)$ AS A, Exp(-[C]*[date $\left.\left.\operatorname{dif}\right]\right)-$ $\operatorname{Exp}\left(-[\mathrm{k}]^{*}[\mathrm{RT} / \mathrm{V}]^{*}[\mathrm{date} \operatorname{dif}]\right) \mathrm{AS} \mathrm{b},[\mathrm{A}]^{*}[\mathrm{~b}] \mathrm{AS}[\mathrm{H} 2 \mathrm{kPa} @ \mathrm{~T}],[\mathrm{A}]^{*}[\mathrm{~b}]^{*} 298 /[\mathrm{T}] \mathrm{AS}\left[\mathrm{H} 2 \_\mathrm{kPa} @ 298 \mathrm{~K}\right]$, tblPCDProcessed.SiteID, IIf([tblPCDProcessed].[SiteID] $=1$ Or [tblPCDProcessed].[SiteID]=3,99.49,IIf([tb1PCDProcessed].[SiteID]=2,78.2,IIf([tblPCDProcessed].[SiteID]=4,81.22,IIf([tbl PCDProcessed].[SiteID] =5,101.33,-9999)))) AS [AtmosPress_kPa@@298K], 50*298/328.15 AS

[OtherGases_kPa_@298K], [H2_kPa_298K]+[OtherGases_kPa_@298K]+[AtmosPress_kPa_@298K]AS

[TAP_kPa_@298K], [TAP_kPa_@298K]-[AtmosPress_kPa_@298K]AS [TGP_kPa_@298K],

[TAP_kPa_@298K]*0.1450377*484.26/[T] AS [TAP_psia_@412F], [TGP_kPa_@298K]*0.1450377*484.26/[T] AS

[TGP_psig_@412F]FROM (((tblPCDInnerCan RIGHT JOIN tbIPCDProcessed ON tblPCDInnerCan.[3013ContainerID] = tblPCDProcessed.[3013ContainerID]) LEFT JOIN tbIPCDConvCan ON tblPCDInnerCan.InnerCanID =

tblPCDConvCan.InnerCanID) LEFT JOIN tbIPCDMoisture ON tbIPCDConvCan.ConvCanID = tblPCDMoisture.ConvCanID) INNER JOIN tbIPCDCalGamma ON tblPCDProcessed.[3013ContainerID] = tblPCDCalGamma.[3013ContainerID]WHERE (((tblPCDMoisture.BestMoisture)=True));

\section{Figure 2-Structured query language (SQL) view of the pressure calculation equation.}




\subsection{Required Information}

The query uses the same variables and input values that were identified in the math calculations but requires linkages to specific tables within the ISP database. Input variables and calculated values are shown below.

\subsubsection{Input Variables}

$\begin{array}{clcc}\text { Variable } & \text { Database Input Value } & \text { Database Unit } & \text { Database Table } \\ \text { N/A } & \text { 3013 Container ID } & \text { Text } & \text { tblPCDProcessed } \\ m & \text { ConvCanNet } & \mathrm{g} & \text { tblPCDConvCan } \\ m_{C C} & \text { ConvCanTare } & \mathrm{g} & \text { tblPCDConvCan } \\ \text { N/A } & \text { BestMoisture } & \text { Boolean } & \text { tblPCDMoisture } \\ w t_{.} \% H_{2} O & \text { MoisturePercent } & \% & \text { tblPCDMoisture } \\ m_{P u(g)} & \text { Pu Measured } & \mathrm{g} & \text { tblPCDCalGamma } \\ m_{A m(g)} & \text { Am Measured } & \mathrm{g} & \text { tblPCDCalGamma } \\ m_{U(g)} & \text { U Measured } & \mathrm{g} & \text { tblPCDCalGamma } \\ m_{N p(g)} & \text { Np Measured } & \mathrm{g} & \text { tblPCDCalGamma } \\ t_{\text {intital }} & \text { InnerCanDateTimeofWeld } & \text { Date/Time } & \text { tblPCDInnerCan } \\ t_{\text {current }} & \text { Pressure Calculation End Date } & \text { Date/Time } & \text { N/A } \\ V_{C o n t a i n e r} & \text { VolInnerCont } & \mathrm{L} & \text { tblPCDProcessed } \\ G & \text { GValue } & \text { number } & \text { tblPCDProcessed } \\ Q & \text { Wattage } & \text { W } & \text { tblPCDCalGamma } \\ \text { N/A } & \text { Site ID } & \text { Integer/Text } & \text { tblPCDProcessed }\end{array}$

\subsubsection{Calculated Input Values}

\begin{tabular}{|c|c|}
\hline Variable & Database Calculation \\
\hline$T_{C}$ & T: [tblPCDCalGamma]![Wattage] $* 3+[\text { tblPCDCalGamma]![Wattage }]^{*} 1.6+25+273$ \\
\hline$S A$ & SA: [tblPCDCalGamma]![Wattage]/[tblPCDConvCan]![ConvCanNet]*1,000 \\
\hline$f_{\mathrm{H}_{2} \mathrm{O}}$ & $\begin{array}{l}\text { f-H2O: } \operatorname{IIf([tblPCDMoisture]![MoisturePercent}]<0,0 \\
\text { [tblPCDMoisture]![MoisturePercent }] / 100\end{array}$ \\
\hline$f_{P_{u}}$ & f-Pu: $\mathrm{nz}([\mathrm{Pu}$ Measured $(\mathrm{g})]) / \mathrm{nz}([$ ConvCanNet $])$ \\
\hline$f_{\text {Am }}$ & f-Am: $\mathrm{nz}([$ Am Measured $(\mathrm{g})]) / \mathrm{nz}([$ ConvCanNet $])$ \\
\hline$f_{U}$ & f-U: nz([U Measured (g)]]/nz ([ConvCanNet]) \\
\hline$f_{N p}$ & f-Np: nz([Np Measured (g)])/nz([ConvCanNet] $)$ \\
\hline$f_{P_{u} O_{2}}$ & f-PuO2: $\left(\mathrm{nz}([\mathrm{Pu} \text { Measured }(\mathrm{g})] / \mathrm{nz}([\mathrm{ConvCanNet}]))^{*} 1.134\right.$ \\
\hline$f_{\mathrm{AmO}_{2}}$ & f-AmO2: $(\mathrm{nz}([$ Am Measured $(\mathrm{g})] / \mathrm{nz}([$ ConvCanNet $])) * 1.132$ \\
\hline$f_{U_{3} O_{8}}$ & f-U3O8: $\left(\mathrm{nz}\left([\mathrm{U}\right.\right.$ Measured $(\mathrm{g})] / \mathrm{nz}([\mathrm{ConvCanNet]}))^{*} 1.179$ \\
\hline
\end{tabular}




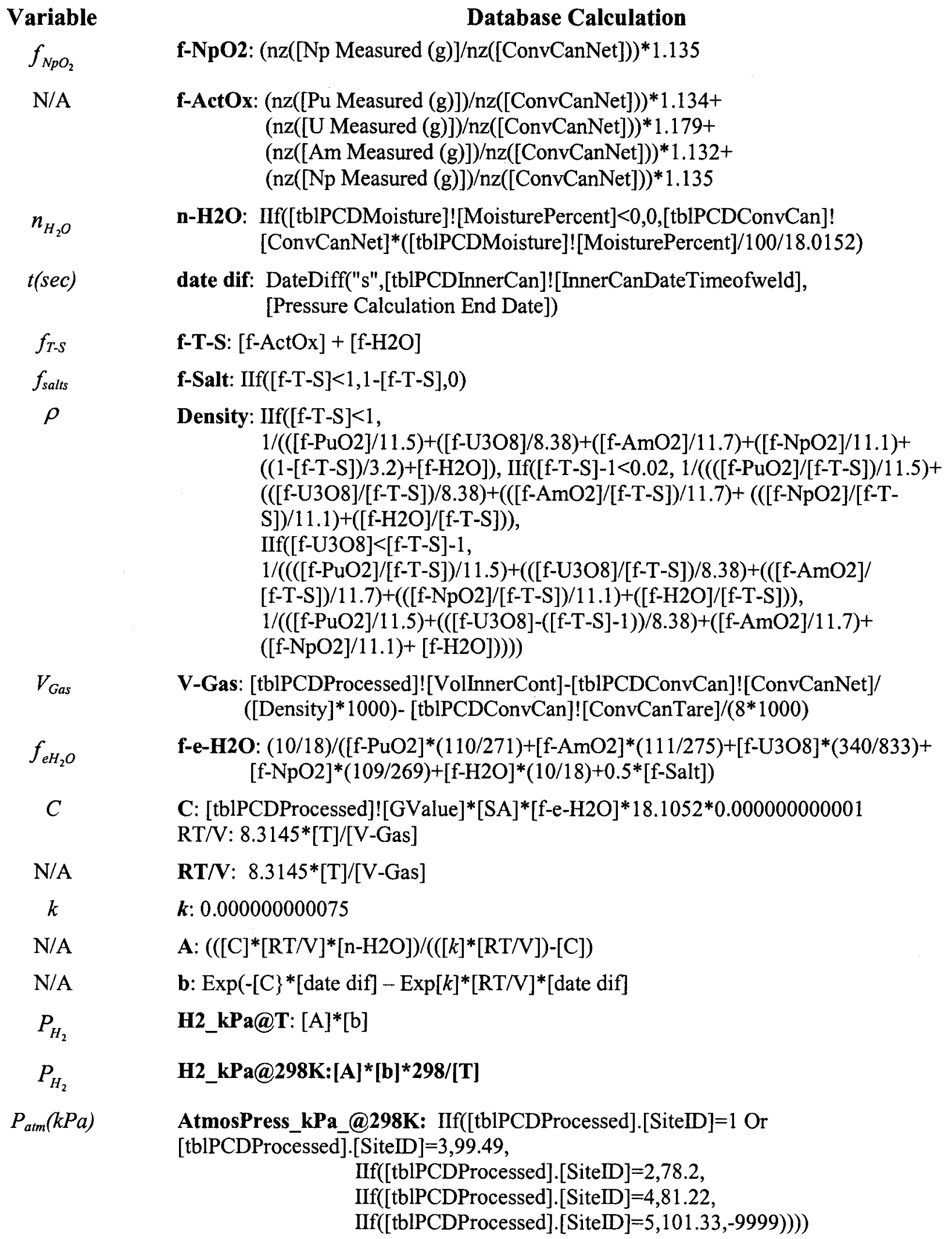




$$
\begin{aligned}
& \text { Variable } \\
& P_{\text {atm }}(p s i)
\end{aligned}
$$

$P_{\text {Other Gases }}(k P a)$

$P_{\text {TAP@298K }}(\mathrm{kPa})$

$P_{T G P}(k P a)$

$P_{T G P}(p s i)$

$P_{\text {TAP }\left(484^{\circ} \mathrm{K}\right)}$ (psia)

\section{Database Calculation}

AtmosPress_psi_@298: IIf([tblPCDProcessed].[SiteID]=1 Or [tblPCDProcessed].[SiteID]=3,14.4, IIf([tblPCDProcessed].[SiteID] $=2,11.3$, IIf([tblPCDProcessed]. [SiteID] $=4,11.8$, IIf([tblPCDProcessed].[SiteID $]=5,14.7,-9999))))$

OtherGases_kPa_@298K: 50*298/328.15

TAP_kPa_@298K:

[H2_kPa_@298]+[OtherGases_kPa_@298K]+[AtmosPress_kPa_@298K]

TGP_kPa_@298K: [TAP_kPa_@298K]-[AtmosPress_kPa_@298K]

TGP_psig_@412F: [TAP_kPa_@298K*0.1450377*484.26/[T]

TAP_psia_412F: ([TAP_kPa_@298K]*0.1450377*484.26/[T]) 


\subsection{VERIFICATION OF CALCULATIONS - AN EXAMPLE}

The following example calculates hydrogen pressure from oxides containing chloride as a function of time and is based on a $G$ value of 200. Density and volume are defined in Equations 11 and 12, respectively. Average gas temperature is calculated using Equation 13.

\subsection{Input Values}

$$
\begin{aligned}
& \mathrm{Pu}=70.643 \% \\
& \mathrm{Am}=0.138 \% \\
& \text { Moisture }=0.2887 \% \\
& \mathrm{~m}=3,337.8 \mathrm{~g} \\
& \mathrm{~m}_{\mathrm{cc}}=1,635.0 \mathrm{~g} \\
& \mathrm{Q}=5.9468 \mathrm{w} \\
& \mathrm{V}_{\text {Container }}=2.217 \mathrm{~L}
\end{aligned}
$$

Weld date $=2$ July 2003

As of date $=1$ February 2005

\subsection{Density, Volume, And Temperature Calculations}

$$
\begin{aligned}
& f_{P_{u O}}=f_{P u} \times 1.134=(70.643 / 100) \times 1.134=0.80109162 \\
& f_{U_{3} O_{8}}=f_{U} \times 1.179=0 \times 1.179=0 \\
& f_{\mathrm{NpO}_{2}}=f_{\mathrm{Np}} \times 1.132=0 \times 1.132=0 \\
& f_{\mathrm{AmO}_{2}}=f_{A m} \times 1.135=(0.138 / 100) \times 1.135=0.0015663 \\
& f_{\mathrm{H}_{2} \mathrm{O}}=(0.2887 / 100)=0.002887 \\
& f_{T-S}=f_{\mathrm{PuO}_{2}}+f_{U_{3} \mathrm{O} 8}+f_{\mathrm{NpO}_{2}}+f_{\mathrm{AmO}_{2}}+f_{\mathrm{H}_{2} \mathrm{O}} \\
& f_{T-S}=0.80109162+0+0+0.0015663+0.002887=0.80554492
\end{aligned}
$$

Since $f_{T-S}$ is less than 1 then $f_{\text {salts }}$ is defined by equation 7:

$$
\mathrm{f}_{\text {salts }}=\left\lfloor 1-\mathrm{f}_{\mathrm{T}-\mathrm{S}}\right\rfloor=1-0.80554492=0.19445508
$$

and the density is then calculated by equation 11 as:

$$
\begin{aligned}
& \rho=\frac{1}{\frac{0.80109163}{11.5}+\frac{0}{8.38}+\frac{0}{11.1}+\frac{0.0015663}{11.7}+\frac{0.002887}{1.0}+\frac{0.19445508}{2.5}} \\
& \rho=\frac{1}{0.06966014+0.00013387+0.002887+0.07778203}=6.65 \mathrm{~g} / \mathrm{cm}^{3} \\
& \mathrm{~V}_{\text {gas }}=\mathrm{V}_{\text {container }}-\frac{\mathrm{m}}{\rho \times 1000}-\frac{\mathrm{m}_{\mathrm{CC}}}{\rho_{\mathrm{SS}} \times 1000}=2.217-\frac{3333.7}{6.6462 \times 1000}-\frac{1635}{8.0 \times 1000}
\end{aligned}
$$




$$
\begin{aligned}
& \mathrm{V}_{\text {gas }}=2.217-0.50131-0.20438=1.511 \mathrm{~L} \\
& T_{C}=3 Q+1.6 Q+25+273=(3 \times 5.9468)+(1.6 \times 5.9468)+298=325.36^{\circ} K \\
& \Delta \mathrm{t}=\mathrm{t}_{\text {current }}-\mathrm{t}_{\text {initial }}=(2 / 1 / 2005)-(7 / 2 / 2003)=580 \text { days } \\
& \mathrm{t}=\Delta \mathrm{t} \times 86400=580 \times 86400=50,112,000 \mathrm{sec} \text { onds }
\end{aligned}
$$

\subsection{Pressure Calculation:}

Results from hand calculations using the hydrogen pressure equation (equation 14) and associated equations are given below:

$$
\begin{aligned}
& \mathrm{SA}=5.9468 \mathrm{w} / 3337.8 \mathrm{~g} \times 1 \times 10^{3} \mathrm{~g} / \mathrm{kg}=1.7817 \mathrm{w} / \mathrm{kg} \\
& \mathrm{f}_{\mathrm{e}-\mathrm{H} 2 \mathrm{O}}=(10 / 18) /[0.8011(110 / 271)]+0+0+[0.00156(111 / 275)+[0.1944(1 / 2)]+[0.00288(10 / 18)] \\
& =0.5555 / .3252+.00063+.0972+.0016=1.3083 \mathrm{~g} / \mathrm{mol} \\
& \mathrm{T}=4.6 \times 5.9468 \mathrm{w}+298 \mathrm{~K}=325.36 \mathrm{~K} \\
& \mathrm{~V}=2.217 \mathrm{~L}-(3337.8 \mathrm{~g} / 6.646 \mathrm{~g} / \mathrm{mL})-(1,635 \mathrm{~g} / 8 \mathrm{~g} / \mathrm{mL})=1.511 \mathrm{~L} \\
& \mathrm{RT} / \mathrm{V}=8.314 \mathrm{~L}-\mathrm{kPa} / \mathrm{K}-\mathrm{mol} \times 325.36 \mathrm{~K} / 1.511 \mathrm{~L}=1,790 \mathrm{kPa} / \mathrm{mol} \\
& k \mathrm{RT} / \mathrm{V}=7.5 \times 10^{-11} \mathrm{~mol} / \mathrm{s}-\mathrm{kPa} \times 1790 \mathrm{kPa}-\mathrm{w} / \mathrm{mole}=1.3425 \times 10^{-7} \mathrm{~s}^{-1} \\
& \mathrm{C}=200 \mathrm{nmol} / \mathrm{W}-\mathrm{s} \times 1.782 \mathrm{w} / \mathrm{kg} \times 1.3083 \times 18.0152 \mathrm{~g} / \mathrm{mol} \times \mathrm{mol} / 1 \times 10^{9} \mathrm{nmol} \times \mathrm{kg} / 1 \times 10^{3} \mathrm{~g}=8.4 \times 10^{-9} \mathrm{~s}^{-1} \\
& \mathrm{n}_{\mathrm{H} 20}=3.3378 \mathrm{~kg} * .002887 / .0180152 \mathrm{~kg} / \mathrm{mol}=0.53489 \mathrm{~mol}^{-1} \\
& e^{(-8.399 \times 10-9)(5.00832 \times 10-7)}-e^{(-1.34 \times 10-7)(5.00832 \times 10-7)}=e^{-.4206}-e^{-6.72}=0.656-0.001=0.655 \\
& \mathrm{P}_{\mathrm{H} 2 @ \mathrm{~T}}=\left[8.4 \times 10^{-9} \mathrm{~s}^{-1} \times 1790 \mathrm{kPa} / \mathrm{mol} \times 0.53489 \mathrm{~mol}^{-1} / 1.3425 \times 10^{-7} \mathrm{~s}^{-1}-8.4 \times 10^{-9} \mathrm{~s}^{-1}\right] \times 0.655= \\
& =63.95 \mathrm{kPa} \times 0.655=41.86 \mathrm{kPa}
\end{aligned}
$$

$\mathrm{P}_{\mathrm{H} 2 @ 298 \mathrm{~K}}=41.86 \mathrm{kPa} \times 298 / 325.36=38.34 \mathrm{kPa}$

$\mathrm{P}_{\text {Other Gases @298K }}=50 \mathrm{kPa} \times 298 / 328.15=45.41 \mathrm{kPa}$

Total Absolute Pressure (TAP) @ 298K = 38.34 kPa $+45.36 \mathrm{kPa}+81.2 \mathrm{kPa}=164.9 \mathrm{kPa}$

Total Gauge Pressure (TGP) @ $298 \mathrm{~K}=(164.9 \mathrm{kPa}-81.2 \mathrm{kPa})=83.7 \mathrm{kPa}$

Total Absolute Pressure $@ 412 \mathrm{~F}(\mathrm{psia})=164.9 \times 0.1450377 \times 484.26 / 325.36=35.6 \mathrm{psia}$

Total Gauge Pressure (TGP) @ 412F = 83.8 $\times 0.1450377 \times 484.26 / 325.36=18.1$ psig 


\subsection{RESULTS AND DISCUSSION}

A comparison of results from hand calculations with results from the ISP data base query showed comparable or identical values (Table 3). Differences were attributable to the number of significant figures and rounding error. These results demonstrate that the query correctly duplicates pressure estimation calculated manually as defined by Equation 14.

Table 3. Comparison of hand calculations with query results for selected variables.

\begin{tabular}{|c|c|c|}
\hline Variable & \multicolumn{2}{|c|}{ Results } \\
\hline & Manual Calculation & Query Generated \\
\hline Density $\left(\mathrm{g} / \mathrm{cm}^{3}\right)$ & 6.65 & 6.646 \\
\hline$\overline{\mathrm{SA}(\mathrm{w} / \mathrm{kg})}$ & 1.782 & 1.782 \\
\hline $\mathrm{f}_{e}-\mathrm{H}_{2} \mathrm{O}$ (unitless) & 1.3083 & 1.3083 \\
\hline $\mathrm{T}_{C}\left({ }^{\circ} \mathrm{K}\right)$ & 325.36 & 325.355 \\
\hline$t(\mathrm{~s})$ & $50,112,000$ & $50,083,200$ \\
\hline $\mathrm{V}(\mathrm{L})$ & 1.51 & 1.51 \\
\hline $\mathrm{RT} / \mathrm{V}(\mathrm{kPa} / \mathrm{mol})$ & 1790 & 1791 \\
\hline$k \mathrm{RT} / \mathrm{V}\left(\mathrm{s}^{-1}\right)$ & $1.34 \mathrm{E}-07$ & $1.34 \mathrm{E}-07$ \\
\hline $\mathrm{C}\left(\mathrm{s}^{-1}\right)$ & $8.4 \times 10^{-9}$ & $8.3986 \times 10^{-9}$ \\
\hline $\mathrm{n}_{\mathrm{H} 2 \mathrm{O}}\left(\mathrm{mol}^{-1}\right)$ & 0.5353 & 0.5348 \\
\hline $\mathrm{P}_{\mathrm{H} 2 @ \mathrm{~T}}(\mathrm{kPa})$ & 41.86 & 41.87 \\
\hline $\mathrm{P}_{\mathrm{H} 2 @ 298 \mathrm{~K}}(\mathrm{kPa}$ & 38.34 & 38.36 \\
\hline $\mathrm{TAP}_{@ 298 \mathrm{~K}}(\mathrm{kPa})$ & 164.9 & 165.0 \\
\hline $\operatorname{TAP}_{@ 412 \mathrm{~F}}$ (psia) & 35.6 & 35.61 \\
\hline $\mathrm{TGP}_{@ 298 \mathrm{~K}}(\mathrm{kPa})$ & 83.7 & 83.76 \\
\hline TGP @412F (psig) & 18.1 & 18.08 \\
\hline
\end{tabular}

Given that the mathematics of the pressure equation and query are in agreement, it is desirable to compare observations in the field with predicted values. In 2007, ten 3013 containers were destructively evaluated at SRS. This process involved the collection of gas samples prior to puncturing the inner container. A gas evaluation software tool (GEST) was then used to calculate actual pressure and gas composition within the 3013 container (Arnold, 2008). The containers were also evaluated using digital radiography (DR) which examined structural characteristics of the container lids and walls. A comparison of pressure values estimated by the pressure equation with those from digital radiography and GEST is shown in Figure 2. 


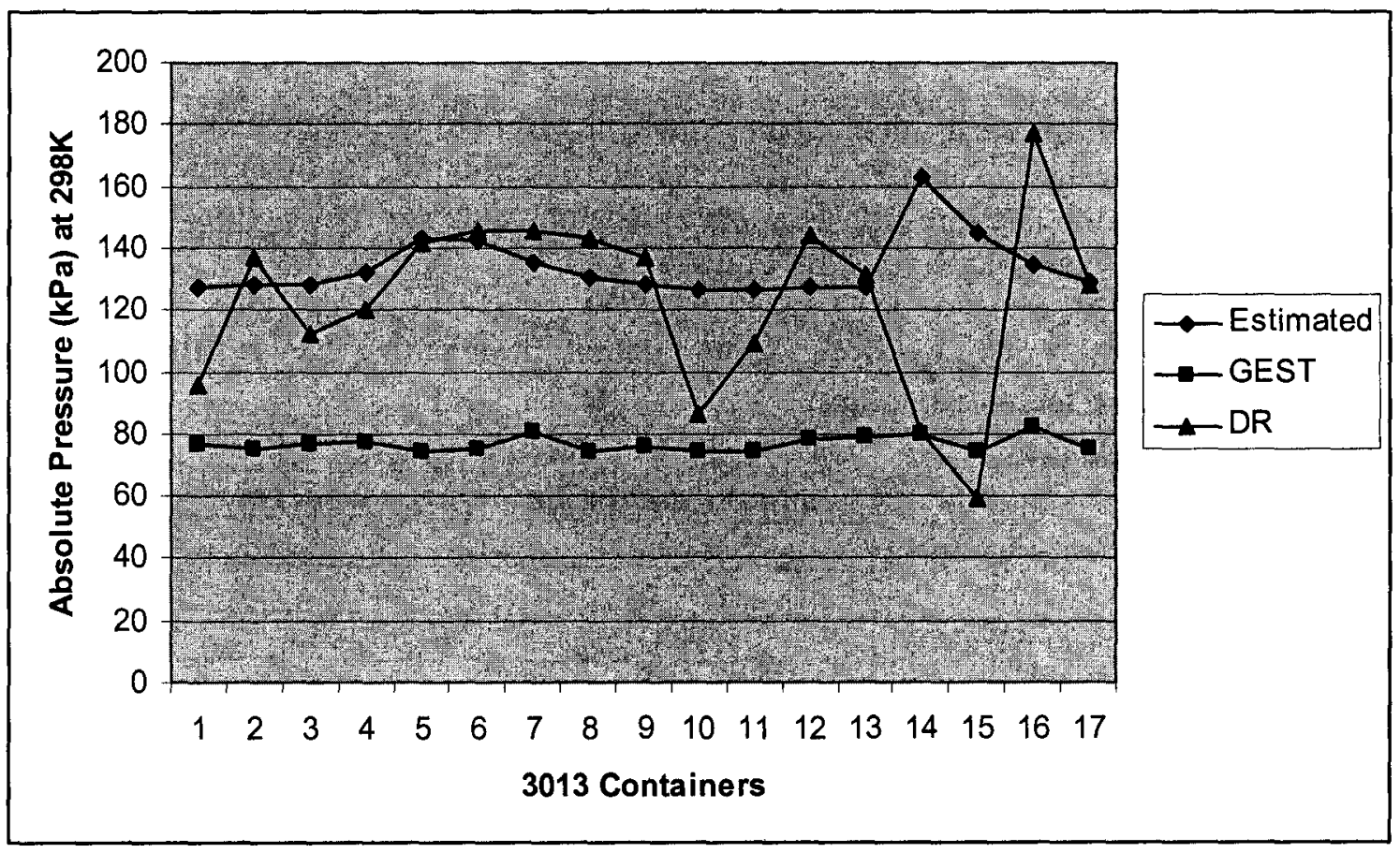

Figure 2. A comparison of absolute pressure $(\mathrm{kPa})$ at $298 \mathrm{~K}$ for 3013 inner containers as determined by the gas evaluation software tool (GEST), digital radiography (DR), and the pressure equation.

The upper line in Figure 2 represents the predicted pressure from the equation which is entered on the pre-surveillance data report (PSDR). Based on the destructive evaluation of 17 containers, the estimated mean absolute pressure was significantly higher $(\mathrm{P}<.01)$ than the mean GEST pressure. There was no significant difference $(\mathrm{P}>.10)$ between the mean pressures from $\mathrm{DR}$ and the calculation. The mean predicted absolute pressure was consistently higher than GEST by an average difference of $57 \mathrm{kPa}(8 \mathrm{psi})$. The mean difference between the estimated pressure and digital radiography was 11 $\mathrm{kPa}(2 \mathrm{psi})$. The predicted total absolute pressure from the pressure equation was generally higher but similar to results from digital radiography and destructive evaluation for the 17 containers. 


\subsection{CONCLUSIONS}

The mathematical approach used in the current calculation reproduces the shape of the hydrogen gas generation curve with time as measured on some MIS small scale test materials. For multiple samples of the same material, it correctly incorporates the dependence upon water. Based on the initial destructive evaluation of 17 containers, the calculation provides an estimate of the gas pressure that is reasonable for predicting worst case or bounding pressures. The estimated maximum pressure of 163 $\mathrm{kPa}$ was markedly lower than the DOE threshold of $4,927 \mathrm{kPa}$. Compared to destructive evaluations and digital radiography, the calculation's inherent conservative values result in higher pressure estimates, but they are similar to results from digital radiography and destructive evaluations. By adopting appropriate maximum $\mathrm{G}$ values and minimum loss terms the calculation improves upon existing estimates of the hydrogen pressure over calculation based on linear extrapolations over time using initial hydrogen $\mathrm{G}$ values.

\subsection{REFERENCES}

Andersen, Virginia. 2001. Access 2002: The Complete Reference. Osborne/McGraw-Hill, Berkeley, California, $1,220 \mathrm{pp}$.

Arnold, M. J. 2008.3013 Gas composition Software Evaluation. ESR-Engineering Studies Report YESR-K-00003, Washington Savannah River Company.

Berg, J., Carillo, A., Garcia, E. Martinez, M., Padilla, D., Veirs, K., Worl, L., Harradine, D., and McInroy, R. 2007a.. Small-Scale Surveillance and Oxygen Generation, FY07 S\&M Program Review, Los Alamos National Laboratory, LA-UR-07-1371.

Berg, J., Carillo, Martinez, M., Veirs, K., Worl, L., Harradine, D., and McInroy, R. 2007b. Predicting the future gas composition of MIS material 011589A, Los Alamos National Laboratory, LA-UR-077870 .

Bielenberg, P.A., F.C. Prenger, D.K. Veirs, and G.F. Jones. 2006. Effects of pressure on thermal transport in plutonium oxide powder. International J. of Heat and Mass Transfer 49:3229-3239.

DOE. April 2004. DOE Standard: Stabilization, Packaging, and Storage of Plutonium-Bearing Materials. U.S. Department of Energy, DOE-STD-3013-2004, Washington, D.C.

Hackney, E.R.. 2007a. Volume Determination for Rocky Flats Environmental Technology Site (RFETS) 3013 Containers. WRSC Document U-CLC-K-00005, 23 October 2007, Washington Savannah River Company, Aiken, SC.

Hackney, E.R.. 2007b. Volume Determination for SRS and Hanford 3013 Inner Containers. WRSC Document U-CLC-K-00006, 5 November 2007, Washington Savannah River Company, Aiken, SC.

Peppers, L.G., E.J. Kelly, D.K. Veirs, and J.M. Berg. 2005. 3013 Container Statistical and Judgmental Samples Selected for Non-Destructive Evaluation (NDE) in FY 2005, LA-UR-05-2193, 41pp. 
WSRC-STI-2008-00214

Rev. 0

This page intentionally left blank. 